\title{
Impact of the first COVID-19 lockdown in Germany on the rate of acute infections during intensive chemotherapy for Hodgkin lymphoma
}

\author{
Anne Sophie Jacob ${ }^{1,3} \cdot$ Helen Kaul ${ }^{1,3} \cdot$ Michael Fuchs $^{1,3} \cdot$ Sarah Gillessen $^{1,3} \cdot$ Stefanie Kreissl $^{1,3}$. \\ Annette Pluetschow ${ }^{1,3}$. Jesko Momotow ${ }^{1,3} \cdot$ Valdete Schaub $^{4} \cdot$ Andreas Huettmann $^{5} \cdot$ Mathias Haenel $^{6}$. \\ Andreas Zimmermann ${ }^{7}$. Judith Dierlamm ${ }^{8}$. Julia Meissner ${ }^{9}$. Stephan Mathas ${ }^{10}$. Sonja Martin ${ }^{11}$. \\ Andreas Engert $^{1,3} \cdot$ Michael Hallek $^{1,2} \cdot$ Peter Borchmann ${ }^{1,3} \cdot$ Clara Lehmann $^{1,2,12,13}$
}

Received: 23 November 2021 / Accepted: 28 January 2022 / Published online: 19 February 2022

(c) The Author(s) 2022

\begin{abstract}
Purpose Evidence on the effect of self-protection via social distancing and wearing face-masks on infections during chemotherapy is currently not available. We asked if the occurrence of acute infections during chemotherapy for advanced-stage Hodgkin lymphoma (HL) decreased when COVID-19 protection measures were in effect.

Methods We analyzed the occurrence of infections during all documented eBEACOPP cycles starting between 01 March and 30 June of 2017 to 2020 in patients treated within the GHSG HD21 study in Germany and compared the infection rates and characteristics by logistic regression models and means of descriptive statistics.

Results We analyzed 911 cycles of 313 adult patients treated with 4 to 6 cycles of eBEACOPP. We found a significant decrease in the occurrence of infections during chemotherapy for HL during COVID-19 lockdown from 131 (19.6\%) of 670 cycles in 2017-2019 to 30 (12.6\%) of 239 cycles during COVID-19 lockdown [OR 0.574 (95\% CI 0.354-0.930), $P=0.024$ ]. The strongest effect was evident for unspecified infections with 39 cycles (5.8\%) during 2017-2019 in comparison to 5 cycles (2.1\%) during COVID-19 lockdown. 20 (24.1\%) of 83 patients had an infection during the COVID-19 lockdown versus 99 (43.2\%) of 229 patients in the years $2017-2019(P=0.0023)$.

Conclusion The significant decrease of infections during chemotherapy for HL during COVID-19 lockdown reveals the protective measures' potential to shield patients from transmissible pathogens. We conclude that these measures could be recommended for HL patients at risk for infections during chemotherapy.
\end{abstract}

Keywords COVID-19 $\cdot$ Hodgkin lymphoma $\cdot$ Infection $\cdot$ Prophylaxis

Peter Borchmann

peter.borchmann@uk-koeln.de

1 Department I of Internal Medicine, Center for Integrated Oncology Aachen Bonn Cologne Duesseldorf, University of Cologne, Faculty of Medicine and University Hospital Cologne, Kerpener Str. 62, 50937 Cologne, Germany

2 CECAD Center of Excellence on Cellular Stress Responses in Aging-Associated Diseases, Center for Molecular Medicine Cologne, Cologne, Germany

3 German Hodgkin Study Group (GHSG), University of Cologne, Cologne, Germany

4 Eberhard-Karls-Universität-Universitätsklinik Tübingen, Inneren Medizin II, Tübingen, Germany

5 Universitätsklinik Essen, Klinik Für Hämatologie/WTZ Ambulanz, Essen, Germany

6 Klinikum Chemnitz, Krankenhaus Küchwald, Klinik Für Innere Medizin III/Studiensekretariat, Chemnitz, Germany
7 Medizinische Klinik Und Poliklinik III, Klinikum Der Universität München, LMU München, Munich, Germany

8 Abt. Hämatologie/Onkologie, Onkologisches Zentrum, Universitätsklinikum Hamburg-Eppendorf, Hamburg, Germany

9 Universitätsklinikum Heidelberg, Medizinische Klinik Und Poliklinik V, Heidelberg, Germany

10 Charite Campus Benjamin Franklin, Universitätsmedizin Berlin, Hämatologie, Onkologie u. Tumorimmunologie, Berlin, Germany

11 Robert-Bosch-Krankenhaus Stuttgart, Innere Medizin II, Hämatologie/Onkologie, Stuttgart, Germany

12 Center for Molecular Medicine Cologne (CMMC), 50937 Cologne, Germany

13 German Center for Infection Research (DZIF), Bonn-Cologne, Cologne, Germany 


\section{Introduction}

Acute infections and fever under chemotherapy are an important cause of morbidity and mortality in hematologic malignancies [1-8]. For patients with advanced-stage Hodgkin lymphoma (HL) in particular, treatment-related morbidity rates of up to $66 \%$ can be observed, depending on the chemotherapy's intensity $[3,4,9,10]$ : treatmentrelated Common Terminology Criteria for Adverse Events (CTCAE) Grade 3/4 infections are documented in up to $17 \%$ of the patients and febrile neutropenia in $33 \%$ of the patients [10]. Therefore, prophylactic anti-infective medication is prescribed frequently, although evidence for positive effects in patients with lymphatic malignancies is limited [5, 8]. Another measure to decrease the rate of infections might be prophylactic self-isolation and avoiding contact to potential sources of infection. In addition, wearing face masks in case of unavoidable contacts might protect against infectious diseases. However, it is still an unanswered question, if these measures are actually effective in this regard. Accordingly, current guidelines do not cover them so far $[5,8]$.

On January 27, 2020, the first case of an infection with SARS-CoV-2 in Germany was reported. Subsequently, infection rates for SARS-CoV-2 increased rapidly throughout the country so that the German government implemented several protection measures to slow down the spreading of the virus, following recommendations by the World Health Organization (WHO) [11-13]. These measures included closing non-essential businesses, schools, universities and gastronomy, implementing the obligation to wear facemasks in public spaces and most importantly, prophylactic social distancing $[11,14]$. Possibly due to the generally high acceptance of these measures, the infection rates continuously dropped over the following months from a maximum of approximately 6500 new infections per day in the beginning of April to around 500 new infections per day in Mid of June 2020 [15]. The protection measures in the public health system apparently had an impact on reducing the rate of infection with SARS-CoV-2 in Germany [16].

This observation raises the question whether these measures would generally prevent the spreading and transmission of respiratory viruses causing influenza and other infections through droplets or direct contact and thereby also reduce the incidence of various infectious complications in cancer patients treated with chemotherapy.

Between July 2016 and August 2020, thus covering periods before and during lockdown measures, we have conducted a controlled, prospective, randomized study in adults with newly diagnosed, advanced-stage Hodgkin lymphoma (GHSG HD21, NCT02661503). Patients in the standard group were treated with eBEACOPP (doseescalated bleomycin, etoposide, doxorubicin, cyclophosphamide, vincristine, procarbazine and prednisolone), an intensive outpatient polychemotherapy regimen. Fever and infections are the most frequent and clinically relevant complications of this treatment [3]. Consequently, the HD21 trial provides a uniformly treated and welldocumented patient cohort, which might allow describing differences between the periods before and during lockdown in the incidence of infections or fever and possibly to derive recommendations from these observations.

We thus aimed to evaluate whether the occurrence of acute infections during chemotherapy for advanced-stage HL decreased since the Corona Virus Disease 2019 (COVID-19) protection measures have been in effect in this well-defined and controlled study population being at high risk for infectious complications.

\section{Methods}

The main aims of our analysis were to assess whether the rate of chemotherapy cycles with acute infections had decreased since COVID-19 protection measures were in effect and to explore possible confounders for a change in infection rates. Our analysis is based on all documented eBEACOPP cycles that started between 01 March and 30 June of any year within the GHSG HD21 study among patients recruited in Germany. Cycles starting between March and June 2020 are being compared with cycles starting between March and June of 2017-2019. This sample was chosen to account for seasonal variation in infection rates. Given that the duration of study treatment is about 3-5 months and hence single patients are not exclusively treated within or outside of the period of interest (01 March-30 June of any year), we analyzed chemotherapy cycles rather than patients and selected those cycles that started in the respective period.

HD21 is an international, randomized phase III study for patients with newly diagnosed advanced stages of HL, including Ann Arbor stages IIB (with a large mediastinal mass or extranodal involvement as risk factors), IIIA/B, and IVA/B. Patients at the age of 18-60 years were randomized to receive PET-guided 4-6 cycles of either eBEACOPP or the experimental BrECADD (brentuximab vedotin, etoposide, cyclophosphamide, doxorubicin, dacarbazine and dexamethasone) regimen (Supplementary material Appendix). The study is performed in accordance with the Declaration of Helsinki and the International Conference on Harmonization guidelines for good clinical practice and registered at ClinicalTrials.gov (NCT02661503). The institutional review board approved this study and all subjects gave written informed consent. 
Recruitment for the study started in July 2016 and was completed in August 2020; however, as results are still pending, we limited our analysis to patients in the control group receiving eBEACOPP. Our analyses are based on the database excerpt for the 9th statistical monitoring report with data cut-off on November 02, 2020. Of note, these are preliminary data and queries may be pending. Acute infections were documented either on the chemotherapy eCRF, including CTCAE grade, type of etiologic agent (bacterial, viral, fungal or not done) and whether or not the infection caused febrile neutropenia, or, in case of serious adverse events (SAEs), in the safety database including CTCAE grade and Medical Dictionary for Regulatory Activities (MedDRA) code. All infections, for which no etiologic agent and no specific MedDRA code was available, were classified as "infection not otherwise specified (NOS)".

Main endpoint was the rate of cycles with acute infections, including any documentation of viral, bacterial, fungal and unspecified infections of CTCAE grade 1-4, febrile neutropenia, and any SAE of a predefined list of MedDRA codes (Supplementary material Appendix) during chemotherapy. Secondary endpoints included infection characteristics and the use of supportive measures such as hospitalization, dose level reductions, and intensified antibiotic prophylaxis. As a sensitivity analysis, we also analyzed the rate of infections within the defined period per patient.

We used means of descriptive statistics to explore primary and secondary outcomes and mixed effects logistic regression models with random intercepts to compare outcomes between cycles starting within the COVID-19 protection period (covered by the period 01 March-30 June 2020) with our reference sample (i.e. cycles starting between 01 March and 30 June of 2017-2019). All regression models were adjusted for age of the patient, cycle number, and white blood cell (WBC) count at day 1 of the respective cycle. We used SAS, version 9.4 (SAS Institute) for statistical analyses.

\section{Results}

A total of 911 eBEACOPP cycles from 313 patients was analyzed in this study (Fig. 1). The female:male ratio was 46:54 and median age 32 years (range 18-60 years) in the analyzed patient cohort. There were 99 patients with at least 1 cycle starting within the COVID-19 protection period (01 March-30 June 2020). The baseline demographic characteristics are shown in Table 1.

During the observed period, an infection of any grade was documented in 161 (17.7\%) of all 909 analyzed cycles with sufficient information on adverse events (Fig. 2a). Overall, 119 (38.1\%) of 312 patients with information on adverse events had an infection during the respective periods (Fig. 2b).

Patients aged 30-39 years had the highest proportion of cycles with an infection with 60 of 276 cycles (21.7\%). There was a trend towards lower infection rates with ongoing chemotherapy per patient, with highest rate of infection observed in cycle 1 ( 40 of 195 cycles; 20.5\%).

There was a significantly lower rate of infection during the COVID-19 lockdown period. Infections occurred in $30(12.6 \%)$ of 239 cycles within the COVID-19 lockdown in comparison to a total of $131(19.6 \%)$ of 670 cycles in 2017-2019 [OR 0.574 (95\% CI 0.354-0.930), $P=0.024$ adjusted for age, cycle number and WBC count]. In the reference period, we observed a relatively steady infection rate (range 19.2-19.9\% in the years 2017-2019).

Similar results can be seen for the analyzed patients in the respective period per year: $20(24.1 \%)$ of 83 patients had an infection during the COVID-19 lockdown period in comparison to a total of $99(43.2 \%)$ of 229 patients in the respective period of the years 2017-2019 [range 37.3-48.0\%; OR 0.405 (95\% CI 0.226-0.725), $P=0.0023$ adjusted for age, number of applied cycles and baseline WBC count; Table 2].
Fig. 1 Analysis set. $e B E A$ COPP dose-escalated bleomycin, etoposide, doxorubicin, cyclophosphamide, vincristine, procarbazine and prednisolone. $B r E C A D D$ brentuximab vedotin, etoposide, cyclophosphamide, doxorubicin, dacarbazine and dexamethasone

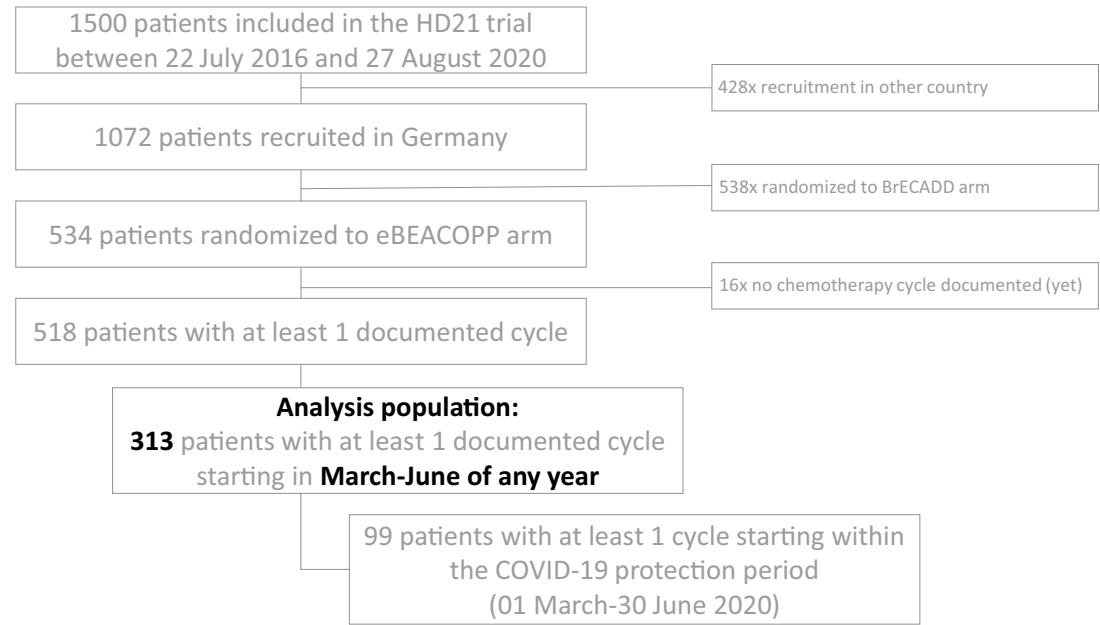


Table 1 Baseline characteristics of analyzed and non-analyzed patients

\begin{tabular}{|c|c|c|c|}
\hline & $\begin{array}{l}\text { Not analyzed } \\
(N=205)\end{array}$ & $\begin{array}{l}\text { Analyzed } \\
(N=313)\end{array}$ & $\begin{array}{l}\text { Total } \\
(N=518)\end{array}$ \\
\hline \multicolumn{4}{|l|}{ Age (years) } \\
\hline Median (range) & $31(18-60)$ & $32(18-60)$ & $31(18-60)$ \\
\hline \multicolumn{4}{|l|}{ Sex } \\
\hline Female & $89(43 \%)$ & $143(46 \%)$ & $232(45 \%)$ \\
\hline Male & $116(57 \%)$ & $170(54 \%)$ & $286(55 \%)$ \\
\hline \multicolumn{4}{|l|}{ Time of recruitment } \\
\hline Median (range) & $10 / 2018(07 / 2016-08 / 2020)$ & $\begin{array}{l}02 / 2019 \\
(11 / 2016- \\
06 / 2020)\end{array}$ & $\begin{array}{l}12 / 2018(06 / 2016- \\
08 / 2020)\end{array}$ \\
\hline \multicolumn{4}{|l|}{ Number of documented cycles } \\
\hline Median (range) & $4(1-6)$ & $4(1-6)$ & $4(1-6)$ \\
\hline \multicolumn{4}{|c|}{ Number of documented cycles in March to June of any year } \\
\hline Median (range) & - & $3(1-6)$ & $1(0-6)$ \\
\hline \multicolumn{4}{|l|}{ Survival status } \\
\hline Alive & $203(99.0 \%)$ & $310(99.0 \%)$ & $513(99.0 \%)$ \\
\hline Death (1st-line infection) & $1(0.5 \%)$ & - & $1(0.2 \%)$ \\
\hline Death (other) & $1(0.5 \%)$ & $3(1.0 \%)$ & $4(0.8 \%)$ \\
\hline
\end{tabular}

Data presented as $n(\%)$, unless otherwise indicated
Within the documented infectious diseases, the biggest difference between lockdown and the years before can be seen for unspecific infections: there were 39 cycles (5.8\%) with an "Infection NOS" during 2017-2019 in comparison to 5 cycles (2.1\%) during COVID-19 lockdown. Other common infectious complications under chemotherapy such as febrile neutropenia did not show a major difference: There were 37 cycles with febrile neutropenia (5.5\%) in the years 2017-2019 compared to 15 cycles $(6.3 \%)$ during the COVID-19 lockdown. SAEs have been reported in 56 of all analyzed cycles $(6.2 \%)$ with similar rates in the lockdown period and the years before (Table 3 ). Specific infection characteristics can be found in Table 3 .

CTCAE grade $3 / 4$ infections occurred in $65(9.7 \%)$ of 670 cycles in 2017-2019 and in $22(9.2 \%)$ of 239 cycles during the COVID-19 protection period, while there was a strong trend towards fewer low-grade infections of CTCAE grade $1 / 2$ during the COVID-19 lockdown period ( 8 cycles, $3.3 \%$ ) compared with the 2017-2019 reference period (66 cycles, 9.9\%) (Table 3).

We further evaluated the difference in use of supportive measures by period. There was neither a significant difference in hospitalizations during the analyzed cycles [OR 1.048 (95\% CI $0.575-1.910$ ), $P=0.88$ adjusted for age and cycle number] or the rate of dose level reductions [OR 0.901 (95\% CI 0.443-1.833), $P=0.77$ adjusted for age and cycle number] nor the rate of intensified antibiotic prophylaxis [OR 1.138 (95\% CI 0.635-2.040), $P=0.66$ adjusted for age and cycle number]. Detailed information can be found in Table 4.

\section{Discussion}

The COVID-19 lockdown measures have led to a unique situation, in which we could analyze the impact of prophylactic self-isolation and face masking on the incidence of infections during chemotherapy within a uniformly treated and well-documented cohort of mainly young HL patients.

The most important finding of our analysis is the significant and clinically relevant decrease in the rate of infectious complications during the COVID-19 protection period in comparison to the respective periods in the years 2017-2019. During the COVID-19 lockdown, there was a rate of $12.6 \%$ infections in the analyzed cycles in comparison to a rate of approximately $20 \%$ in the previous years. This was also true for the rate of infection per patient with $24.1 \%$ in 2020 compared to $37.3-48.0 \%$ in the years 2017-2019.

This decrease was not equally strong in all subgroups of infections. The strongest effect was evident for infections that were not further classified in the study documentation, i.e. with an unknown type of etiologic agent. We assume that the majority of these is accounted for by environmental pathogens such as viruses causing upper respiratory tract infections, for which the detection rate of any viral pathogen is only up to $36 \%$ even in symptomatic patients [17]. This assumption is supported by our results that show a trend towards fewer low CTCAE grade infections during COVID19 lockdown as compared with the years before.

On the other hand, the rate of febrile neutropenia has stayed relatively stable over the past years and 
Fig. 2 a Analyzed cycles (March-June)_-Infections per year. Missing information on Adverse Events (AEs) in 2/911 cycles. b Analyzed patients (March-June)-Infections per year. Missing information on AEs in $1 / 313$ patients
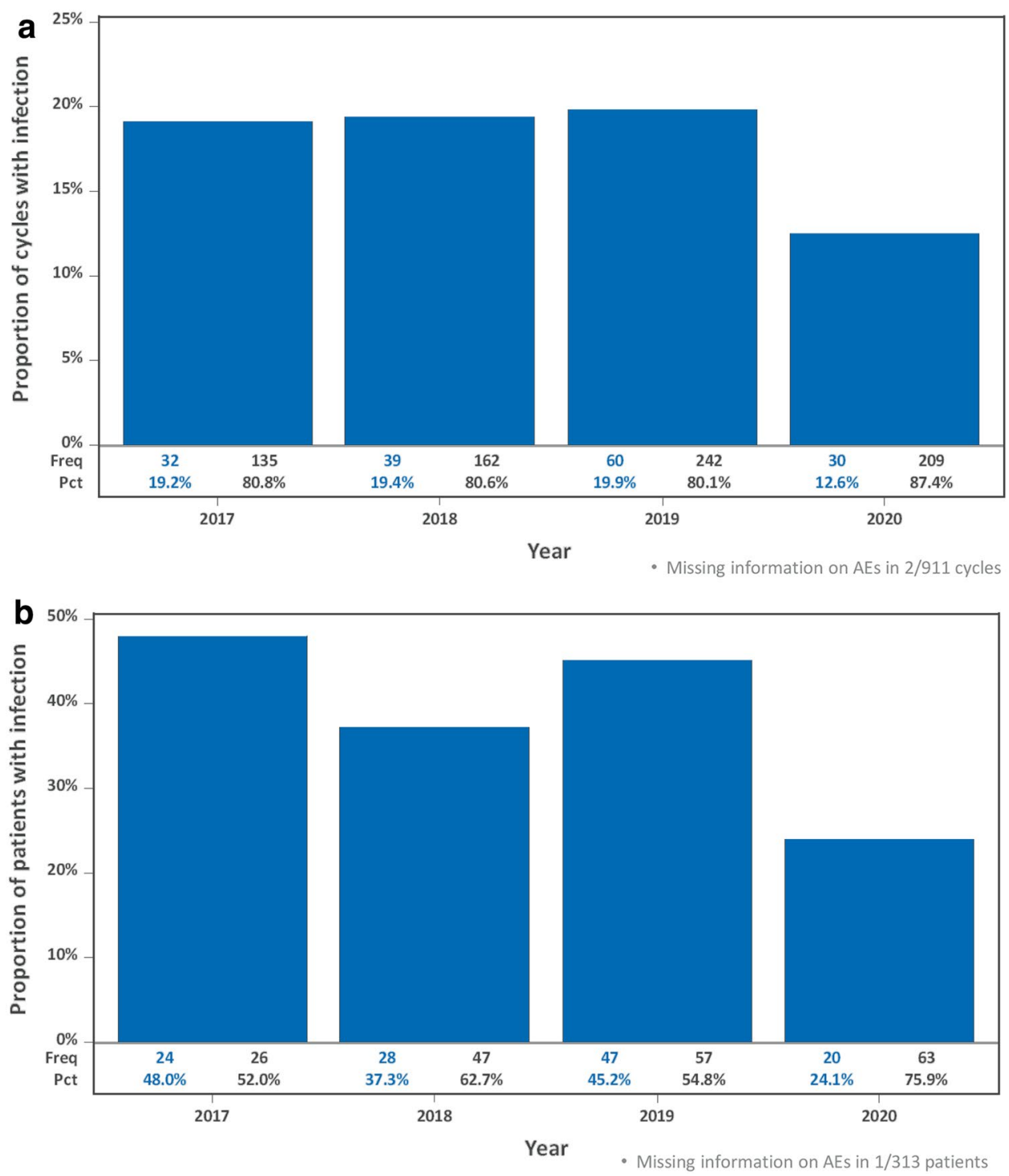

during COVID-19 lockdown. This is in accordance with the assumption that severe neutropenic infections are often caused by pathogens from the patient's individual microbiome, e.g. Escherichia coli infections [18, 19]. Consequently, protection measures such as the ones during COVID-19 lockdown do not have an effect on these more endogenous infections, while exerting a relevant effect on transmitted infections.

Importantly, our findings are in line with data on the activity of several other respiratory viruses in Germany published by the "Clinical Virology Network", which show that the activity of Influenza A was much lower in 2020 than in 2019 . There were only about 430 positive findings for Influenza A in the period of 01 March-30 June 2020, but roughly 4300 positive findings in the respective months of 2019. This is also true for RSV ( 220 positive findings in 2020 vs. $\sim 520$ positive findings in 2019 ) or the Rhinovirus
( $\sim 270$ positive findings in 2020 vs. $~ 750$ positive findings in 2019) [20]. Similar data were presented by Chan et al. who showed that in Hong Kong, the influenza season was 63.2\% shorter, the number of institutional influenza-like-illness (ILI) outbreaks was $68.4 \%$ lower and the number of deaths from influenza (laboratory confirmed) in adults was $62.3 \%$ lower in the 2019-20 influenza season compared to 2015-19 [21]. Hence, our study and similar data [20,21] highlight the effectiveness of the COVID-19 protection measures on the rate of acute infections in the general population and of acute infectious complications in HL patients under chemotherapy.

Limitations of our analysis need to be mentioned. First, the relatively low infection rate in 2020 might be a result of reporting bias since we must assume that more recent documentation is missing more often. In order to exclude an effect of fewer cycles being documented per patient, we primarily analyzed the infection rate among documented 
Table 2 Logistic regression on infections per cycle

\begin{tabular}{|c|c|c|c|c|}
\hline \multicolumn{5}{|l|}{ A) Infections per cycle, $N=908^{\mathrm{a}}$} \\
\hline Parameter & & Odds ratio & $(95 \% \mathrm{CI})$ & $P$ \\
\hline Age at enrollment [8] & Cont & 0.991 & $(0.974-1.008)$ & 0.30 \\
\hline Cycle number & Cont & 1.001 & $(0.877-1.142)$ & 0.991 \\
\hline WBC count at start of cycle & Cont & 1.021 & $(0.988-1.055)$ & 0.21 \\
\hline Cycle start in COVID-19 protection period & Yes vs. No & 0.574 & $(0.354-0.930)$ & 0.024 \\
\hline \multicolumn{5}{|l|}{ A) Infections per patient, $N=312^{\mathrm{b}}$} \\
\hline Parameter & & Odds ratio & $(95 \% \mathrm{CI})$ & $P$ \\
\hline Age at enrollment [8] & Cont & 0.988 & $(0.968-1.009)$ & 0.26 \\
\hline Number of documented cycles & Cont & 1.363 & $(1.149-1.618)$ & 0.0004 \\
\hline Baseline WBC count & Cont & 0.981 & $(0.940-1.023)$ & 0.37 \\
\hline Treated in COVID-19 protection period & Yes vs. No & 0.405 & $(0.226-0.725)$ & 0.0023 \\
\hline
\end{tabular}

a 3 of 911 analyzed cycles excluded due to missing information on adverse events $(n=2)$ or WBC count $(n=1)$

${ }^{b} 1$ of 313 analyzed patients excluded due to missing information on adverse events

Table 3 Infection characteristics per cycle

\begin{tabular}{|c|c|c|c|}
\hline & $\begin{array}{l}\text { Not in COVID-19 } \\
\text { lockdown period } \\
(N=670)(\%)\end{array}$ & $\begin{array}{l}\text { In COVID- } \\
19 \text { lockdown } \\
\text { period } \\
(N=239) \\
(\%)\end{array}$ & $\begin{array}{l}\text { Total } \\
\left(N=909^{\mathrm{a}}\right)(\%)\end{array}$ \\
\hline Any infectious disease & $131(19.6)$ & $30(12.6)$ & 161(17.7) \\
\hline \multicolumn{4}{|l|}{ Infectious disease } \\
\hline Pneumonia & $1(0.1)$ & $2(0.8)$ & $3(0.3)$ \\
\hline Stomatitis & $1(0.1)$ & $1(0.4)$ & $2(0.2)$ \\
\hline Gastroenteritis & $1(0.1)$ & - & $1(0.1)$ \\
\hline Abscess jaw & $1(0.1)$ & - & $1(0.1)$ \\
\hline Sepsis & $1(0.1)$ & - & $1(0.1)$ \\
\hline Urinary tract infection & - & $1(0.4)$ & $1(0.1)$ \\
\hline Febrile neutropenia & $37(5.5)$ & $15(6.3)$ & $52(5.7)$ \\
\hline \multicolumn{4}{|l|}{ Etiologic agent } \\
\hline $\begin{array}{l}\text { Bacteria (Escherichia infection, Staphylococcal sepsis, Campylo- } \\
\text { bacter infection, Klebsiella bacteriaemia) }\end{array}$ & $8(1.2)$ & - & $8(0.9)$ \\
\hline Virus (Herpes/ Herpes zoster) & $1(0.1)$ & $1(0.4)$ & $2(0.2)$ \\
\hline Virus (Varicella zoster, Coronavirus, Influenza B) & $2(0.3)$ & $1(0.4)$ & $3(0.3)$ \\
\hline Fungi (Oral candidiasis, Candida sepsis) & $2(0.3)$ & - & $2(0.2)$ \\
\hline \multicolumn{4}{|l|}{ Not specified } \\
\hline Infection NOS & $39(5.8)$ & $5(2.1)$ & $44(4.8)$ \\
\hline Bacterial infection NOS & $19(2.8)$ & $1(0.4)$ & $20(2.2)$ \\
\hline Viral infection NOS & $11(1.6)$ & $2(0.8)$ & $13(1.4)$ \\
\hline Fungal infection NOS & $5(0.7)$ & - & $5(0.6)$ \\
\hline Bacterial and fungal infection NOS & $2(0.3)$ & $1(0.4)$ & $3(0.3)$ \\
\hline \multicolumn{4}{|l|}{ Highest CTCAE grade } \\
\hline 1 & $34(5.1)$ & $1(0.4)$ & $35(3.9)$ \\
\hline 2 & $32(4.8)$ & $7(2.9)$ & $39(4.3)$ \\
\hline 3 & $58(8.7)$ & $18(7.5)$ & $76(8.4)$ \\
\hline 4 & $7(1.0)$ & $4(1.7)$ & $11(1.2)$ \\
\hline \multicolumn{4}{|l|}{ Severity } \\
\hline Serious & $41(6.1)$ & $15(6.3)$ & $56(6.2)$ \\
\hline Non-serious & 90 (13.4) & $15(6.3)$ & 105 (11.6) \\
\hline
\end{tabular}

Data presented as $n(\%)$

NOS not otherwise specified, CTCAE common terminology criteria for adverse events

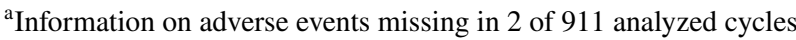


Table 4 Supportive measures per cycle

\begin{tabular}{|c|c|c|c|}
\hline & $\begin{array}{l}\text { Not in COVID-19 } \\
\text { lockdown period } \\
(N=671)\end{array}$ & $\begin{array}{l}\text { In } \\
\text { COVID-19 } \\
\text { lockdown } \\
\text { period } \\
(N=240)\end{array}$ & $\begin{array}{l}\text { Total } \\
(N=911)\end{array}$ \\
\hline \multicolumn{4}{|l|}{ Hospitalization $^{\mathrm{a}}$} \\
\hline Hospitalization during cycle & $313 / 670(46.7)$ & $113(47.1 \%)$ & $426 / 910(46.8 \%)$ \\
\hline Number of hospital days per cycle & $5(1-31)$ & $6(1-20)$ & $5(1-31)$ \\
\hline ICU admission during cycle & $1 / 670(0.1 \%)$ & $1(0.4 \%)$ & $2 / 910(0.2 \%)$ \\
\hline Number of ICU days per cycle & $13 \mathrm{NA}$ & 4 NA & $8.5(4-13)$ \\
\hline \multicolumn{4}{|l|}{ Dose level reductions ${ }^{\mathrm{b}}$} \\
\hline Baseline level & $30(4.5 \%)$ & $12(5.0 \%)$ & $42(4.6 \%)$ \\
\hline Level 1 & $7(1.0 \%)$ & 0 & $7(0.8 \%)$ \\
\hline Level 2 & $\begin{array}{l}30 \\
(4.5 \%)\end{array}$ & $9(3.8 \%)$ & $39(4.3 \%)$ \\
\hline Level 3 & $129(19.2 \%)$ & $49(20.4 \%)$ & $178(19.5 \%)$ \\
\hline Full dose & $475(70.8 \%)$ & $170(70.8 \%)$ & $645(70.8 \%)$ \\
\hline \multicolumn{4}{|l|}{ Prophylaxis } \\
\hline Intensified antibiotic prophylaxis applied & $363(54.1 \%)$ & $139(57.9 \%)$ & $502(55.1 \%)$ \\
\hline $\begin{array}{l}\text { Days with intensified antibiotic prophy- } \\
\text { laxis per cycle }\end{array}$ & $7(1-21)$ & $7(1-21)$ & $7(1-21)$ \\
\hline \multicolumn{4}{|c|}{ Data presented as $n(\%), n /$ Total $(\%)$ or median (range) } \\
\hline \multicolumn{4}{|l|}{$I C U$ intensive care unit, $N A$ not applicable } \\
\hline \multicolumn{4}{|c|}{ 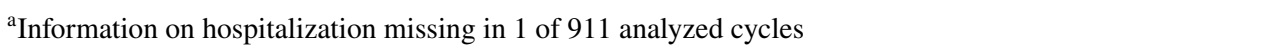 } \\
\hline \multicolumn{4}{|c|}{$\begin{array}{l}\text { beBEACOPP dose levels are defined as follows: full dose: cyclophosphamide } 1250 \mathrm{mg} / \mathrm{m}^{2} \text { on day } 1 \text {, doxo- } \\
\text { rubicin } 35 \mathrm{mg} / \mathrm{m}^{2} \text { on day } 1 \text {, etoposide } 200 \mathrm{mg} / \mathrm{m}^{2} \text { on days } 1-3 \text {, procarbazine } 100 \mathrm{mg} / \mathrm{m}^{2} \text { on days } 1-7 \text {, pred- } \\
\text { nisone } 40 \mathrm{mg} / \mathrm{m}^{2} \text { on days } 1-14 \text {, vincristine } 1.4 \mathrm{mg} / \mathrm{m}^{2} \text { (max. } 2 \mathrm{mg} \text { in total) on day } 8 \text {, and bleomycin } 10 \mathrm{mg} / \\
\mathrm{m}^{2} \text { on day } 8 \text {. Level 3: reduce cyclophosphamide to } 1100 \mathrm{mg} / \mathrm{m}^{2} \text { and etoposide to } 175 \mathrm{mg} / \mathrm{m}^{2} \text {. Level } 2 \text { : } \\
\text { reduce cyclophosphamide to } 950 \mathrm{mg} / \mathrm{m}^{2} \text { and etoposide to } 150 \mathrm{mg} / \mathrm{m}^{2} \text {. Level } 1: \text { reduce cyclophosphamide to } \\
800 \mathrm{mg} / \mathrm{m}^{2} \text { and etoposide to } 125 \mathrm{mg} / \mathrm{m}^{2} \text {. Baseline: reduce cyclophosphamide to } 650 \mathrm{mg} / \mathrm{m}^{2} \text {, doxorubicin to } \\
25 \mathrm{mg} / \mathrm{m}^{2} \text { and etoposide to } 100 \mathrm{mg} / \mathrm{m}^{2}\end{array}$} \\
\hline
\end{tabular}

cycles instead of among patients. Bias might then still occur if documentation of cycles with infection would be missing or delayed more likely than that of cycles without infection. We thus checked the infection rate among cycles starting between May and August 2019 as documented in the dataset from statistical monitoring in 09/2019 vs. $11 / 2020$. In $09 / 2019$ the infection rate was $21 \%$ on the basis of 168 documented cycles, while in 11/2020 it was $20 \%$ among 290 documented cycles. Reporting bias is thus unlikely to influence our results. Second, we recognize that our study cohort consists of mainly young HL patients and observed effects might not be fully applicable to older patients or other cancer patients treated with different regimens. However, the data on the effect of the COVID-19 lockdown measures on the general population included patients from all age groups [15]. Since these data are in line with our results, we assume that the same effect could be observed in older patients or other malignancies as well. Third, due to the retrospective nature of our analysis, we are not able to definitively assess whether the observed effect can be primarily attributed to the patients' self-isolation and face masking or the general decrease of air-borne infections during the lock-down period. While our study can thus not prove a causal relationship, we analyzed the confounding factors thoroughly and conclude that a causal relationship is at least highly probable.

Strengths of our analysis include the large, well-documented, uniformly treated study population. The reporting trial sites included both university hospitals and small practices throughout Germany and therefore mirror the real-world setting. The documentation of infectious complications was thorough so that detailed information could be derived and analyzed. Accordingly, the observed effects seem to be robust and reliable.

In conclusion, we recommend to inform cancer patients on the significant protective effect of prophylactic social distancing and face covering on the occurrence of communicable infections. The reliable evidence derived from our observation may support patients in their decision on whether or not they adopt these protective measures into their life while they are treated with chemotherapy for cancer. 
Supplementary Information The online version contains supplementary material available at https://doi.org/10.1007/s15010-022-01765-3.

Acknowledgements Not applicable.

Author contributions ASJ, PB, HK and CL designed research. ASJ, MF, SG, SK, AP, JM, VS, AH, MH, AZ, JD, JM, SM, and SM collected data. HK and AP performed statistical analyses. ASJ, HK, PB and CL analyzed and interpreted data. ASJ, HK, PB and CL wrote the first draft of the manuscript. All authors contributed to data interpretation, reviewed the draft, and approved the final version of this report.

Funding Open Access funding enabled and organized by Projekt DEAL.

\section{Declarations}

Conflict of interests There are no competing interests.

Open Access This article is licensed under a Creative Commons Attribution 4.0 International License, which permits use, sharing, adaptation, distribution and reproduction in any medium or format, as long as you give appropriate credit to the original author(s) and the source, provide a link to the Creative Commons licence, and indicate if changes were made. The images or other third party material in this article are included in the article's Creative Commons licence, unless indicated otherwise in a credit line to the material. If material is not included in the article's Creative Commons licence and your intended use is not permitted by statutory regulation or exceeds the permitted use, you will need to obtain permission directly from the copyright holder. To view a copy of this licence, visit http://creativecommons.org/licenses/by/4.0/.

\section{References}

1. Diehl V, Franklin J, Pfreundschuh M, et al. Standard and increased-dose BEACOPP chemotherapy compared with COPP-ABVD for advanced Hodgkin's disease. N Engl J Med. 2003;348:2386-95.

2. Evens AM, Hutchings M, Diehl V. Treatment of Hodgkin lymphoma: the past, present, and future. Nat Clin Pract Oncol. 2008;5:543-56.

3. Gafter-Gvili A, Fraser A, Paul M, et al. Antibiotic prophylaxis for bacterial infections in afebrile neutropenic patients following chemotherapy. Cochrane Database Syst Rev. 2012;1:CD004386.

4. Engert A, Goergen H, Markova J, et al. Reduced-intensity chemotherapy in patients with advanced-stage Hodgkin lymphoma: updated results of the open-label, international, randomised phase 3 HD15 trial by the German Hodgkin study group. Hemasphere. 2017;1:e5.

5. Taplitz RA, Kennedy EB, Bow EJ, et al. Antimicrobial prophylaxis for adult patients with cancer-related immunosuppression: ASCO and IDSA clinical practice guideline update. J Clin Oncol. 2018;36:3043-54.

6. Kuderer NM, Dale DC, Crawford J, et al. Mortality, morbidity, and cost associated with febrile neutropenia in adult cancer patients. Cancer. 2006;106:2258-66.
7. Carmona-Bayonas A, Jimenez-Fonseca P, Virizuela Echaburu J, et al. Prediction of serious complications in patients with seemingly stable febrile neutropenia: validation of the clinical index of stable febrile neutropenia in a prospective cohort of patients from the FINITE study. J Clin Oncol. 2015;33:465-71.

8. Baden LR, Swaminathan S, Angarone M, et al. Prevention and treatment of cancer-related infections, version 2.2016, NCCN clinical practice guidelines in oncology. J Natl Compr Cancer Netw. 2016;14:882-913.

9. Dalal M, Gupta J, Price K, et al. Efficacy and safety of front-line treatments for advanced Hodgkin lymphoma: a systematic literature review. Expert Rev Hematol. 2020;13:907-22.

10. Borchmann P, Goergen H, Kobe C, et al. PET-guided treatment in patients with advanced-stage Hodgkin's lymphoma (HD18): final results of an open-label, international, randomised phase 3 trial by the German Hodgkin Study Group. Lancet. 2018;390:2790-802.

11. Bundesministerium für Gesundheit D. Coronavirus SARS-CoV-2: Chronik der bisherigen Maßnahmen. In Edition Bundesministerium für Gesundheit, Deutschland 2020. https://www.bundesgesu ndheitsministerium.de/coronavirus/chronik-coronavirus.html.

12. Robert-Koch-Institut. Täglicher Lagebericht des RKI zur Coronavirus-Krankheit-2019 (COVID-19) In 12.03.2020 -AKTUALISIERTER STAND FÜR DEUTSCHLAND, Edition 2020. https:// www.rki.de/DE/Content/InfAZ/N/Neuartiges_Coronavirus/Situa tionsberichte/2020-03-12-en.pdf?_blob=publicationFile.

13. World-Health-Organisation. Novel Coronavirus(2019-nCoV) Situation Report - 22. In Edition 2020. https://apps.who.int/iris/ handle/10665/330991.

14. Presseamt und Informationsamt der Bundesregierung D. Maskenpflicht in ganz Deutschland. In Edition Presse- und Informationsamt der Bundesregierung Deutschland 2020. https://www. bundesregierung.de/breg-de/themen/coronavirus/maskenpflichtin-deutschland-1747318.

15. Robert-Koch-Institut. Robert Koch-Institut: COVID-19-Dashboard. In Edition Berlin: 2020. https://experience.arcgis.com/ experience/478220a4c454480e823b17327b2bf1d4.

16. Robert-Koch-Institut. Täglicher Lagebericht des RKI zur Coronavirus-Krankheit-2019 (COVID-19) 28.10.2020_aktualisierter stand für deutschland. In Edition 2020. https://www.rki.de/DE/ Content/InfAZ/N/Neuartiges_Coronavirus/Situationsberichte/ Okt 2020/2020-10-28-de.pdf? blob=publicationFile.

17. Sundell N, Andersson LM, Brittain-Long R, et al. PCR detection of respiratory pathogens in asymptomatic and symptomatic adults. J Clin Microbiol. 2019. https://doi.org/10.1128/JCM.00716-18.

18. Carvalho AS, Lagana D, Catford J, et al. Bloodstream infections in neutropenic patients with haematological malignancies. Infect Dis Health. 2020;25:22-9.

19. Al-Tawfiq JA, Hinedi K, Khairallah H, et al. Epidemiology and source of infection in patients with febrile neutropenia: a ten-year longitudinal study. J Infect Public Health. 2019;12:364-6.

20. Kaiser R, Amas O. Aktivität respiratorischer Viren. In Edition Clinical Virology Network. https://clinical-virology.net/de/charts/ chart/ctype/count/network/resp/section/viruses.

21. Chan KH, Lee PW, Chan CY, et al. Monitoring respiratory infections in covid-19 epidemics. BMJ. 2020;369:m1628. 